\title{
Physico-chemical Study of the Adsorption of Methyl Orange from Water by Biosorbent and Activated Carbon Based on Peanut Shells
}

\author{
Etienne Yanne $^{1}$, Eric Noubissiè ${ }^{2,}$, , Daniele Kada Benessoubo ${ }^{1}$, Marie Charlène Eko ${ }^{1}$, \\ Jean Baptiste Bike Mbah ${ }^{1}$ \\ ${ }^{1}$ Department of Applied Chemistry, National School of Agro-Industrial Sciences, Ngaoundere, Cameroon \\ ${ }^{2}$ Department of Chemical Engineering, University Institute of Technology, Ngaoundere, Cameroon
}

Email address:

noubissieerik@yahoo.fr (E. Noubissié), eric.noubissie@univ-pau.fr (E. Noubissié)

${ }^{*}$ Corresponding author

\section{To cite this article:}

Etienne Yanne, Eric Noubissié, Daniele Kada Benessoubo, Marie Charlène Eko, Jean Baptiste Bike Mbah. Physico-chemical Study of the Adsorption of Methyl Orange from Water by Biosorbent and Activated Carbon Based on Peanut Shells. Journal of Energy, Environmental \& Chemical Engineering. Vol. 6, No. 2, 2021, pp. 37-44. doi: 10.11648/j.jeece.20210602.12

Received: July 1, 2021; Accepted: July 14, 2021; Published: July 21, 2021

\begin{abstract}
The objective of this work is to study the elimination of Methyl Orange (MO) contained in wastewater, by adsorption on four different adsorbents, produced from peanut shells. To achieve this, the various adsorbents were first produced. The native biosorbent $(\mathrm{BN})$ was obtained from drying, crushing and sieving the peanut shells. The activated biosorbent (BA) was obtained by chemical activation with ortho-phosphoric acid $\left(\mathrm{H}_{3} \mathrm{PO}_{4}\right) 10 \% \mathrm{BN}$. The activated carbons (CA1 and CA2) were obtained by pyrolysis at $650^{\circ} \mathrm{C}$ of $\mathrm{BN}$ and $\mathrm{BA}$, respectively. The four products were characterized adsorbents and experiments to determine the effects of $\mathrm{pH}$, contact time, of their masses and the concentration of methyl orange in its removal by adsorption was carried out. The results show that the thermal activation of the BN has multiplied its surface area by 11 , while chemical activation has multiplied by its specific surface 8 . Both treatment (chemical and thermal) have also tripled the micropores of BN. All four adsorbents have a maximum adsorption capacity at $\mathrm{pH} 6$. At this $\mathrm{pH}$, the amount of MO adsorbed decreases with increase in its concentration, regardless of the adsorbent used. Likewise, adsorption equilibrium is reached at $3 \mathrm{~min}$ on the four adsorbents. The pseudo second order model describes the adsorption kinetics of $\mathrm{MO}$ on the four adsorbents. Ultimately, CA1 is found to be the most effective in removing $\mathrm{MO}$ from wastewater.
\end{abstract}

Keywords: Peanut Shells, Acid Treatment, Heat Treatment, Biosorbent, Activated Carbon, Methyl Orange, Wastewater

\section{Introduction}

Water pollution, by certain industrial chemicals including dyes, is a major source of environmental degradation in several countries. Methyl orange (MO) is one of the most widely used dyes in the textile, stationery, cosmetics and food industries [1]. Once dissolved in water, it is sometimes difficult to remove due to its synthetic origin and the complexity of its molecular structure, which makes it stable and difficult to biodegrade [2]. Methyl orange (MO) is a dye that is dangerous for the health of populations living in contaminated surface water. Its ingestion through the consumption of such water can cause cancerous diseases and deformities [3, 4]. This justifies the importance of its elimination in effluents before they are released into nature.

Overall, different processes are used for the treatment of wastewater loaded with synthetic pollutants. These are, for example, physicochemical and adsorption processes on different solid materials $[5,6]$. Adsorption appears to be the most widely used process for the removal of MO [1, 7-9]. All of the work carried out on the elimination of MO in wastewater is focused on the preparation of the adsorbent material. In this logic, the objective is to obtain effective and efficient adsorbents at a lower cost. This is what justifies so much interest in the high use of lignocellulosic waste from fruit trees [10], palm waste [11], sawdust [12], date pits [13] 
or palm kernel seed shells [1], as the main substrate for the manufacture of adsorbents, whether they are biosorbents or activated carbon. The present work follows the same logic, through the use of peanut shells, which constitute waste, to manufacture biosorbents and activated carbon. These two types of adsorbents will be used to remove the MO contained in wastewater.

\section{Material and Methods}

\subsection{Origin and Characterization of the Substrate}

The adsorbent materials were produced from peanut shells of the Virginia variety. These shells constitute waste available in Cameroon for more than 6 months of each year. They were collected from households in the town of Ngaoundéré (Cameroon).

\subsubsection{Determination of the Water and Dry Matter Content of the Substrate}

The dry matter and water contents were determined by differential weighing of a known quantity of substrate $(5 \mathrm{~g})$, before and after drying at $105^{\circ} \mathrm{C}$ for 24 . The dry matter (DM) is expressed as a percentage of fresh matter according to the equation (1).

$$
\% \mathrm{DM}=\frac{M_{2}-M_{0}}{M_{1}-M_{0}} \times 100
$$

$\mathrm{M}_{0}=$ mass $(\mathrm{g})$ of the empty crucible; $\mathrm{M}_{1}=$ mass $(\mathrm{g})$ of the crucible containing the substrate before baking; $\mathrm{M}_{2}=$ mass (g) of the crucible containing the substrate after baking. The water content $(\mathrm{Wc})$ in $\%$ reduces to the dry matter content by equation (2).

$$
\% \mathrm{Wc}=100-\mathrm{DM}
$$

\subsubsection{Determination of Total Ash Content}

The ash content was evaluated by determining the loss of mass by burning a quantity of substrate $(1 \mathrm{~g})$ at $550^{\circ} \mathrm{C}$ in a muffle furnace. The ash content ( $\%$ AC) was calculated by differential weighing between the amount of initial dry matter and that collected at the end of the calcination operation.

\subsection{Preparation of Adsorbents}

The peanut shells collected were successively washed with tap water, then dried at $50^{\circ} \mathrm{C}$ to a constant weight. They were then crushed and packaged in a closed jar. The product resulting from these pretreatment operations constitutes our native biosorbent $(\mathrm{BN})$.

A quantity of this $\mathrm{BN}$ was chemically activated with orthophosphoric acid $\left(\mathrm{H}_{3} \mathrm{PO}_{4}\right)$ to $10 \%$ for 24 hours in the bath set at $80^{\circ} \mathrm{C}$ to facilitate diffusion of the acid into the material. After 24 hours of chemical activation, the activated product was washed thoroughly with distilled water until the $\mathrm{pH}$ was stabilized. In order to desorb water bound to the structure of the material, the washed sample was dried at $105^{\circ} \mathrm{C}$. The dried adsorbent material was crushed and sieved $(<100 \mu \mathrm{m})$.
The product resulting from this process constitutes our activated biosorbent (BA).

An amount of $\mathrm{BN}$ and $\mathrm{BA}$ was pyrolyzed at $650^{\circ} \mathrm{C}$ in a muffle furnace. The product of the pyrolysis was ground and sieved $(100 \mu \mathrm{m})$. The various products resulting from this heat treatment constitute our two activated carbon (CA). These are CA1 that is the activated carbon based on $\mathrm{BN}$, and CA2 that is the activated carbon based on BA. The four adsorbents produced (BN, BA, CA1 and CA2) were subsequently characterized.

\subsection{Characterisation of Adsorbents}

\subsubsection{Microporosity of Adsorbents}

The microporosity of the different adsorbents was determined through the iodine index, according to the method used by Djonga et al. [14]. In fact, $0.5 \mathrm{~g}$ of each dry adsorbent was mixed with $50 \mathrm{ml}$ of an iodine solution $(0.1 \mathrm{~N})$ in a beaker. After stirring at $250 \mathrm{rpm}$ for $5 \mathrm{~min}$, the mixture was filtered and $10 \mathrm{ml}$ of the filtrate were pipetted and introduced into a conical flask with $0.5 \mathrm{ml}$ of a $1 \%$ prepared starch solution. The solution tinted to dark blue and the reaction between iodine and starch was titrated with sodium thiosulfate $\left(\mathrm{Na}_{2} \mathrm{~S}_{2} \mathrm{O}_{3}\right.$ at $\left.0.1 \mathrm{~N}\right)$ until complete bleaching of the mixture. The iodine index was calculated following the equation (3).

$$
\text { Iodine index }=\frac{\left(\mathrm{V}_{\mathrm{b}}-\mathrm{V}_{\mathrm{e}}\right) N_{\text {thio }} \times \mathrm{M}_{\mathrm{I}_{2}} \times 1,5}{\mathrm{~m}_{\mathrm{A}}}
$$

$\mathrm{V}_{\mathrm{b}}=$ volume of sodium thiosulfate used for the blank $(\mathrm{mL}) ; \mathrm{V}_{\mathrm{e}}=$ volume of sodium thiosulfate used to determine the iodine solution after adsorption $(\mathrm{mL}) ; \mathrm{N}_{\text {sthio }}=$ normality of sodium thiosulfate $(0.1 \mathrm{~N}) ; \mathrm{M}_{\mathrm{I} 2}=$ molecular mass of Iodine $(253.81 \mathrm{~g} / \mathrm{mol})$ and $\mathrm{m}_{\mathrm{A}}=$ mass of adsorbent used $(0.5 \mathrm{~g})$.

\subsubsection{Macroporosity and Specific Surface Area of Adsorbents}

The macroporosity of the various adsorbents was determined through the methylene blue index, according to the method used by Djonga et al. [14]. Indeed, $0.2 \mathrm{~g}$ of each adsorbent was mixed in a beaker with $100 \mathrm{ml}$ of a methylene blue solution at $20 \mathrm{mg} / \mathrm{L}$. After $20 \mathrm{~min}$ of stirring (at 250 $\mathrm{rpm}$ ), the adsorbent was separated from the solution by filtration. The absorbance of the filtrate was measured on a $\mathrm{UV} /$ visible spectrophotometer (Jenway brand) at $664 \mathrm{~nm}$. But before, a range of calibration solutions had been prepared with concentrations varying from 0 to $10 \mathrm{mg} / \mathrm{L}$ of methylene blue in steps of $1 \mathrm{mg} / \mathrm{L}$ and analysed at the same wavelength. The residual dye concentration was determined using the calibration line. The methylene blue index (MBi) or the adsorption capacity of the adsorbent was calculated following the equation (4).

$$
\operatorname{MBi}(\mathrm{mg} / \mathrm{g})=\frac{\left(\mathrm{C}_{\mathrm{i}}-\mathrm{C}_{\mathrm{f}}\right) \times \mathrm{V}}{\mathrm{m}_{\mathrm{A}}}
$$

$\mathrm{C}_{\mathrm{i}}=$ initial concentration of methylene blue (MB) in the solution; $\mathrm{C}_{\mathrm{f}}=$ concentration of $\mathrm{MB}$ in the solution after adsorption; $\mathrm{V}=$ volume of $\mathrm{MB}$ solution; $\mathrm{m}_{\mathrm{A}}=$ mass of 
adsorbent. The value of the specific surface is deduced from equation (5)

$$
\mathrm{SS}\left(\mathrm{m}^{2} / \mathrm{g}\right)=\mathrm{MBi} \times 20.93
$$

With 20.93 representing the area in $\mathrm{m}^{2}$ of a methylene blue molecule.

\subsubsection{Determination of the Zero Charge Point (pHpcN) of Adsorbents}

The $\mathrm{pH}$ of the zero or zero charge point (pHzcp) corresponds to the $\mathrm{pH}$ value for which the net charge on the surface of the carbon is zero. It was determined using the method used by Soudani et al. [15]. Practically, $50 \mathrm{ml}$ of $\mathrm{NaCl}$ solution $(0.01 \mathrm{M})$ of $\mathrm{pH}$ between 2 and 12 were introduced into closed flasks. The $\mathrm{pH}$ was adjusted by adding $\mathrm{NaOH}$ or $\mathrm{HCl}$ solution $(0.1 \mathrm{M})$. Then, $0.5 \mathrm{~g}$ of adsorbent was added to each flask, then stirred at $250 \mathrm{rpm}$ for 48 hours, at room temperature. The final $\mathrm{pH}$ of the different solutions was determined after stirring using a $\mathrm{pH}$ meter. The $\mathrm{pH}$ at the zero-charge point ( $\mathrm{pHzcp}$ ) obtained, is the point where the function curve $\mathrm{pH}_{\text {final }}=\mathrm{f}\left(\mathrm{pH}_{\text {initial }}\right)$ intercepts the line where $\mathrm{pH}_{\text {final }}=\mathrm{pH}_{\text {initial }}$.

\subsection{Study of the Adsorption of Methyl Orange on the Different Adsorbents}

The study of adsorption of methyl orange (MO) contained in the water to be treated was carried out in batch mode. It consisted of placing $20 \mathrm{~mL}$ of the water to be treated in contact with $0.1 \mathrm{~g}$ of adsorbent, under well-defined conditions depending on the objective to be achieved. Among other things, it was to assess the influence of the initial $\mathrm{pH}$, the effect of the initial concentration of the MO, the contact time and the mass of the adsorbent on the efficiency of adsorption.

\subsubsection{Effect of Initial pH on the Adsorption Capacity of Methyl Orange}

The study of the effect of the initial $\mathrm{pH}$ of the water to be treated on the adsorption capacity of the MO it contains was carried out by adding $0.1 \mathrm{~g}$ of adsorbent to a series of $20 \mathrm{~mL}$ of water to be treated, with the $\mathrm{pH}$ varying from 2 to 8 in steps of 2. The $\mathrm{pH}$ of the water was adjusted by adding $\mathrm{NaOH}$ or $\mathrm{HCl}$ solution $(0.1 \mathrm{M})$. The contents of each reactor, characterized by a specific $\mathrm{pH}$, were stirred for 20 minutes at $250 \mathrm{rpm}$, then separated by filtration. The initial and residual concentrations of $\mathrm{MO}$ were determined.

\subsubsection{Effect of Initial Concentration of Methyl Orange in Treated Water on Adsorption Capacity}

The study of the different effects of the initial concentrations of methyl orange OM contained in the water to be treated on the absorption capacity was carried out with three different initial concentrations $(10 ; 20$ and $40 \mu \mathrm{mol} /$ L). Thus, $20 \mathrm{~mL}$ of each solution was contacted with $0.1 \mathrm{~g}$ of the adsorbent while stirring at $250 \mathrm{rpm}$ at room temperature for $20 \mathrm{~min}$. Then, the initial and residual OM concentrations according to equation (6).

$$
\mathrm{q}=\frac{\left(\mathrm{C}_{\mathrm{i}}-\mathrm{C}_{\mathrm{e}}\right) \times \mathrm{V}}{\mathrm{m}}
$$

In this equation (6), $\mathrm{Ci}$ is the initial concentration of $\mathrm{MO}$ considered, $\mathrm{Ce}$ is the concentration of $\mathrm{MO}$ at equilibrium, $\mathrm{V}$ is the volume of the solution and $m$ is the mass of the adsorbent. The data resulting from these manipulations made it possible to obtain adsorption isotherms, which describe the distribution of MO between the liquid (effluent), and solid (adsorbent) phases. The adsorption isotherms obtained were modeled according to Langmuir, Freundlich, Dubinin-Raduskevich and Temkin according to the methods used by Battas et al. [16], Al-Ghouti et al., [17] and Inyinbor et al., [18].

\subsubsection{Effect of Contact Time and Adsorbent Mass on the Adsorption Capacity of Methyl Orange}

These two effects were monitored at room temperature $\left(20^{\circ} \mathrm{C}\right)$ and at pH6. The effect of the contact time on the adsorption capacity of methyl orange (OM) contained in the water to be treated was studied by bringing a mass of each adsorbent into contact with $20 \mathrm{~mL}$ of this water and stirring at $250 \mathrm{rpm}$. The contact time was varied from 1 to $20 \mathrm{~min}$ in steps of $5 \mathrm{~min}$. The effect of mass was achieved under the same conditions by varying the mass of the adsorbent from 0.01 to $0.1 \mathrm{~g}$. Once equilibrium was reached, the treated water was filtered and the OM adsorption capacity was calculated using the formula shown in equation (6). The kinetics of adsorption of the MO on the adsorbent was studied using two kinetic models, the pseudo first order and pseudo second order models [19].

\section{Results and Discussions}

\subsection{Characteristics of Adsorbents}

\subsubsection{PH at Zero Charge Point of Different Adsorbents}

The $\mathrm{pH}$ at zero charge point ( $\mathrm{pHzcp}$ ) of the different adsorbents can be identified in Figure 1.

It emerges from this figure that the pHzcp of the different adsorbents are 5.98 for $\mathrm{BN}, 4.07$ for BA, 7.92 for $\mathrm{CA} 2$ and 6.80 for CA1. At these $\mathrm{pH}$ values, the charge is zero at the solid surface of each of the respective adsorbents. Thus, if the $\mathrm{pH}$ of the water containing the methyl orange (MO) is lower than the pHzcp, the surface functional groups of the adsorbents will be protonated by an excess of protons $\left(\mathrm{H}^{+}\right)$contained in the solution, causing the attraction of the adsorbates negatively charged If otherwise the $\mathrm{pH}$ of the water to be treated is greater than the pHpcn, the surface functional groups of the adsorbent will be deprotonated by the presence of $\mathrm{OH}$ ions in the solution. This will lead to the attraction of the positively charged adsorbates in the solution. The zwitterionic character of $\mathrm{OM}$ in acid form [1] is a key indicator for understanding the mechanisms of its adsorption on the four adsorbents produced. This means that the MO can be adsorbed on the four adsorbents whatever the nature of the charge on their surfaces. 


\subsubsection{Porosities and Specific Surface Area of Adsorbents}

Information on the porosity and specific surface area of the adsorbents is presented in Table 1.

Table 1. Specific surface area, iodine index and methylene blue index of the adsorbents.

\begin{tabular}{lllll}
\hline Parameters & BN & BA & CA1 & CA2 \\
\hline Iodine index $(\mathrm{mg} / \mathrm{g})$ & 380.7 & 951.75 & 1142.1 & 561.4 \\
BM index $(\mathrm{mg} / \mathrm{g})$ & 3.57 & 29.97 & 40 & 15 \\
Specific surface area $\left(\mathrm{m}^{2} / \mathrm{g}\right)$ & 74.65 & 627.25 & 837.2 & 313.95 \\
\hline
\end{tabular}

BN: native biosorbent; BA: activated biosorbent; $\mathrm{CA} 1$ activated carbon based on BN; CA2 activated carbon based on BA

a) Biosorbent

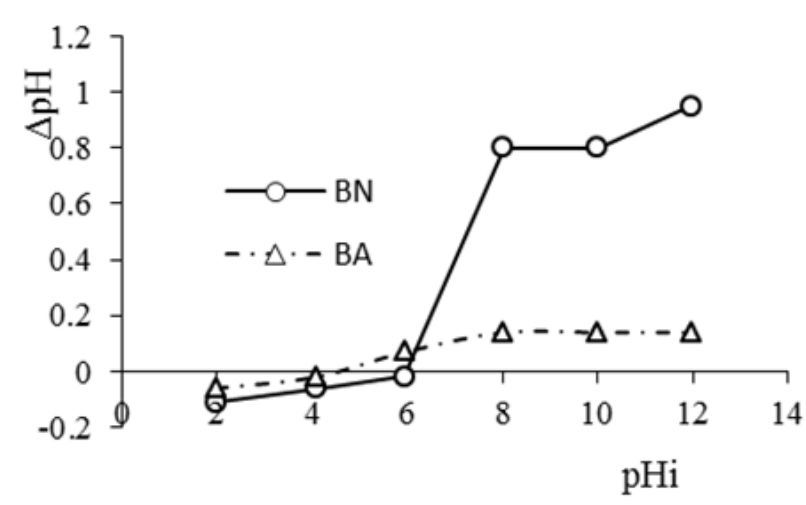

b) Activated carbon

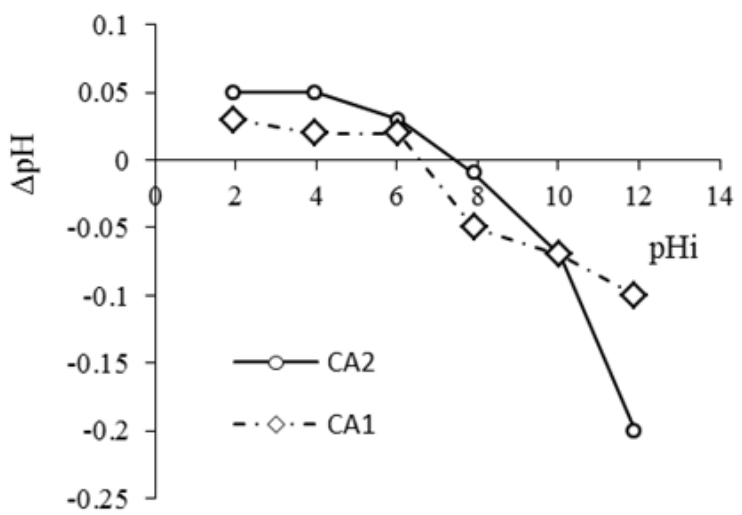

BN: native biosorbent; BA: activated biosorbent; CA1 activated carbon based on BN; CA2 activated carbon based on BA

Figure 1. Variation of the $\mathrm{pH}$ at the surface of the different adsorbents as a function of the initial pH of the solution.

These results reveal that the adsorbents produced are more microporous than macroporous. There is a treatment effect (chemical and thermal) of the adsorbent on its physical characteristics. This treatment effect is characterized by the increase in the specific surface area and the porosity of the biosorbent with the treatment. Table 1 therefore clearly shows that BA has a specific surface area which is 8 times greater than that of $\mathrm{BN}\left(\mathrm{SS}_{\mathrm{BA}}=8 \times \mathrm{SS}_{\mathrm{BN}}\right)$. This means that the chemical activation of $\mathrm{BN}$ made it possible to obtain a new adsorbent with a specific surface area 8 times greater than that of BN. Similarly, thermal activation of BN made it possible to multiply its specific surface area of the new adsorbent by 11 $\left(\mathrm{SS}_{\mathrm{CA} 1}=11 \times \mathrm{SS}_{\mathrm{BN}}\right)$. These two treatments (chemical and thermal) have also made it possible to triple the porosity of the new adsorbents compared to that of $\mathrm{BN}$. The increase in the specific surface area and the porosity of the activated biosorbent (BA) compared to $\mathrm{BN}$ caused by chemical activation, is explained by the expansion of the molecules of celluloses and hemicellulose, followed by the elimination of the extractible which clogged the pores of the substrate. The same effect caused by thermal activation (from BN to CA1) is simply explained by the removal of water from peanut shells and the transformation of its extractable and lignin into charcoal $[11,1]$. Especially since the peanut shells used to produce the four adsorbents, consisted of $6.55 \%$ residual water and $67.71 \%$ volatile dry matter (Table 2 ).

However, these results reveal that thermal activation of the already chemically activated biosorbent leads to a reduction by half of the specific surface area and of the porosity of the new adsorbent obtained $(\mathrm{CA} 2=\mathrm{BA} / 2)$. Indeed, the chemical activation having weakened the celluloses and hemicellulose of peanut shells by dilating them, their thermal activation destroyed some of these molecules. The destruction of these molecules means the destruction of part of the dry matter of the substrate, which was to turn into charcoal. This resulted in the reduction of the pores and the specific surface area of the material.

Table 2. Some physical characteristics of peanut shells.

\begin{tabular}{ll}
\hline Characteristic & Values (\%) \\
\hline WC (water content) & $6.55 \pm 0,50$ \\
AC (Ash content) & $3.62 \pm 0.60$ \\
VM (volatile matter) & $67.71 \pm 0.30$ \\
\hline
\end{tabular}

\subsection{Study of the Adsorption of Methyl Orange on the Four Adsorbents}

\subsubsection{Effect of pH on the Adsorption of Methyl Orange}

Figure 2 shows the results of the effect of varying the $\mathrm{pH}$ of the water to be treated on the efficiency of methyl orange (MO) adsorption.

It can be seen from this figure 2 that the 4 adsorbents reached their best adsorption efficiency at $\mathrm{pH} 6$. Under these conditions, the CA1 are positively charged, than those BN and BA are negatively charged. The acid MO being a zwitterionic [1], it will necessarily be adsorbed by each of the 4 adsorbents. Therefore, the zwitterionic character of the acid $\mathrm{MO}$ in solution is the major criterion, which has favoured its attachment to the four adsorbents, whatever the nature of the 
initial $\mathrm{pH}$ of the medium. Regarding adsorption efficiency, CA1 and BA adsorbents were found to be the most effective in removing $\mathrm{MO}$, regardless of the $\mathrm{pH}$ of the solution. This is justified by their specific surfaces and porosities respectively higher than for $\mathrm{CA} 2$ and $\mathrm{BN}$. Therefore, the maximum adsorption of MO remains strongly influenced by the size of the specific surface and the amount of pores available on the surface of the adsorbent.

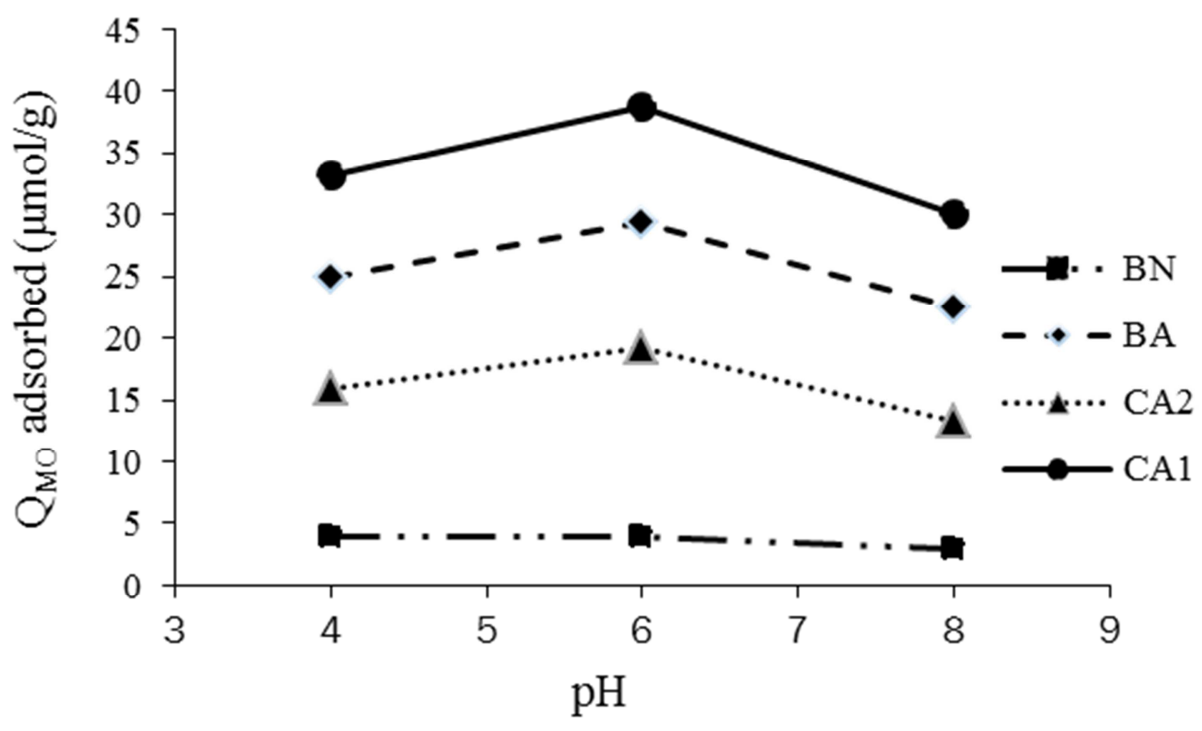

BN: native biosorbent; BA: activated biosorbent; CA1 activated carbon based on BN; CA2 activated carbon based on BA; $\mathrm{QMO}_{\mathrm{MO}}$ quantity of MO adsorbed

Figure 2. Evolution of the quantity of methyl orange (MO) adsorbed on the 4 adsorbents, as a function of pH of the solution.

\subsubsection{Influence of the Concentration of Methyl Orange in Solution on the Efficiency of Its Adsorption}

Figure 3 shows the results of the influence of the initial concentration of methyl orange (OM) in water on the efficiency of its adsorption.

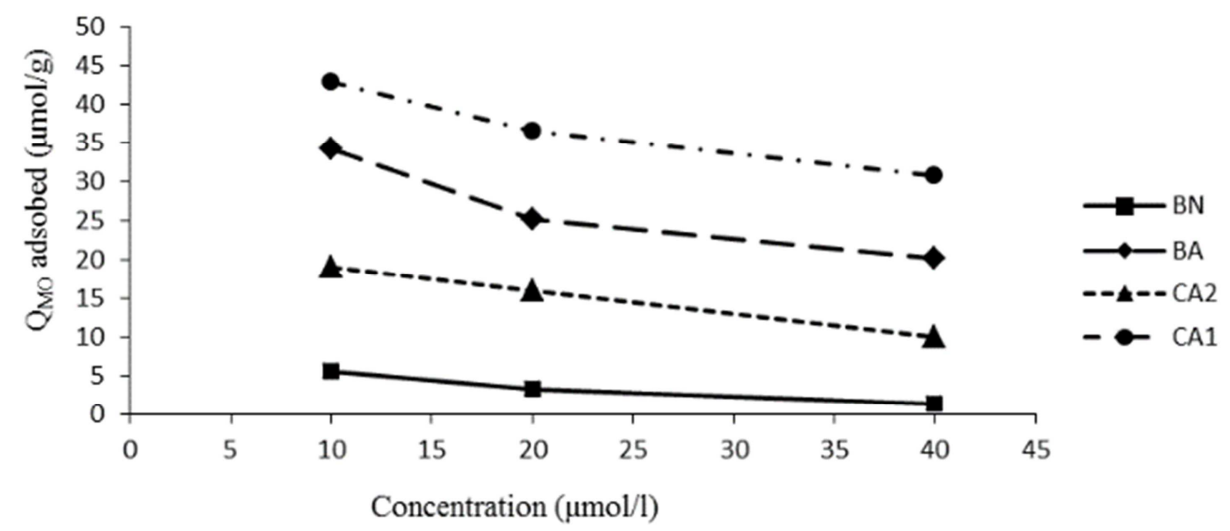

BN: native biosorbent; BA: activated biosorbent; CA1 activated carbon based on BN; CA2 activated carbon based on BA: QM०: quantity of MO adsorbed

Figure 3. Evolution of the quantity of MO adsorbed as a function of its initial concentration in solution.

Overall, it emerges from this Figure 3 that the amount of MO adsorbed decreases with increase in its concentration in water, regardless of the adsorbent used. When the MO concentration is low in solution, this observation is justified by the high ratio between the binding sites available at the surface of the adsorbents and the quantity of MO present in the solution. This promotes the fixation of the maximum amount of $\mathrm{MO}$ on the adsorbent and therefore its optimal elimination from the solution. However, at high MO concentrations, the binding sites available on the surface of the adsorbent do not increase. The driving force due to the concentration gradient is greater and the quantity of $\mathrm{MO}$ adsorbed per unit mass of adsorbent is more important [7]. Those that cause saturation of the sites available on the adsorbent. Once these sites are saturated, the MO molecules that have not found a place on the adsorbent remain in solution. This is what justifies the low MO removal efficiency when its initial concentration is increasingly high.

\subsubsection{Influence of the Mass of the Adsorbent and the Contact time on the Adsorption of Methyl Orange}

Figure 4 shows the results of the influence of adsorbent mass and contact time on the efficiency of MO adsorption. 
BN
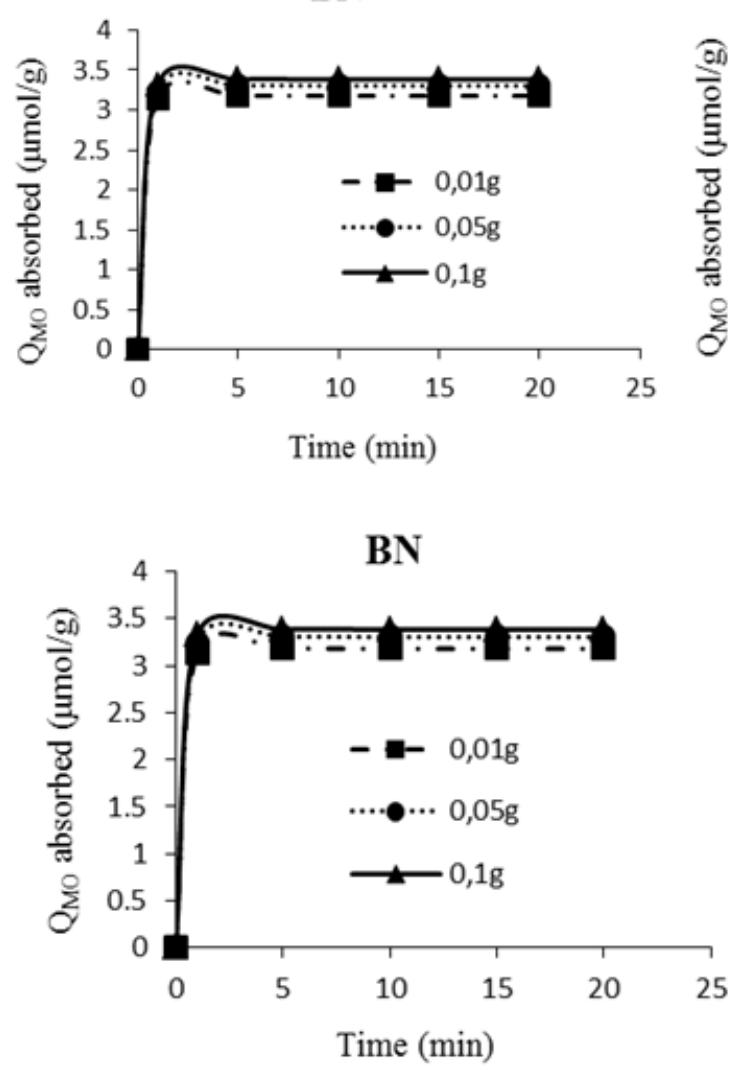

BA

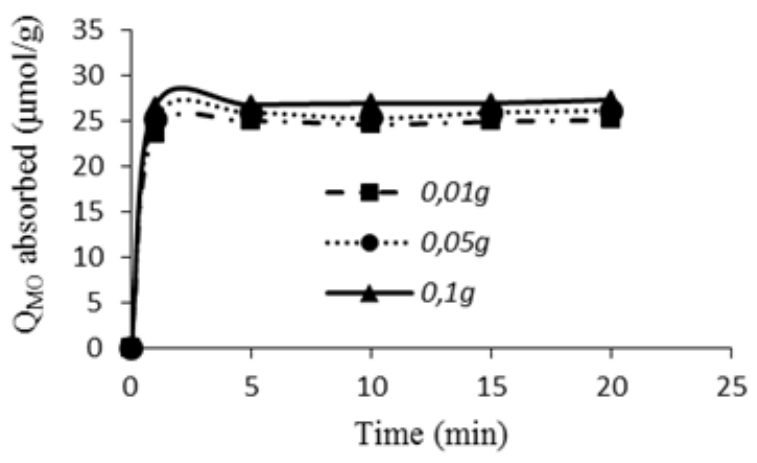

BN

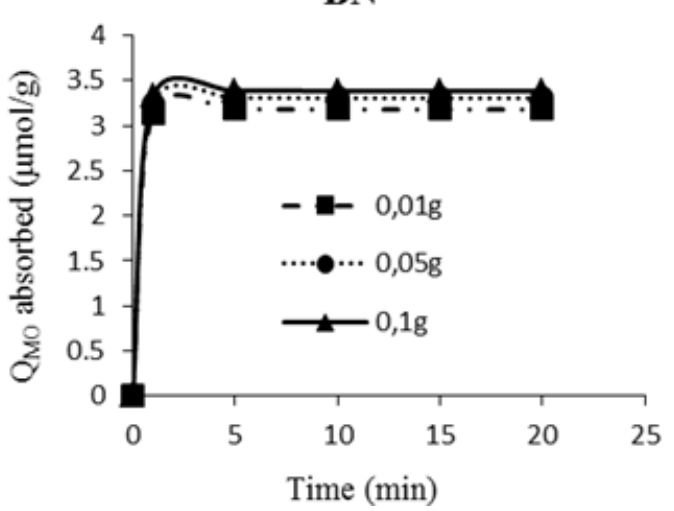

BN: native biosorbent; BA: activated biosorbent; CA1 activated carbon based on BN; CA2 activated carbon based on BA; $\mathrm{Q}_{\mathrm{MO}}$ : quantity of MO adsorbed

Figure 4. Evolution of the quantity of methyl orange (MO) adsorbed as a function of the variation in the mass of the four adsorbents and the contact time.

These results show that the amount of MO adsorbed increases with mass, thus characterizing a positive influence of mass of the adsorbent on the elimination of MO. This makes sense because increasing the mass of the adsorbent in the medium, implies an increase in the binding sites available for MO adsorption [7, 14]. However, this influence of mass of the adsorbent is not significant. The adsorption of MO on the 4 adsorbents being certain, the results characterizing this adsorption mechanism (Table 3) reveal that it best corresponds to the pseudo second order kinetic model $\left(\mathrm{R}^{2}=0.99\right)$. This means that the adsorption of the MO on the available sites of the four adsorbents takes place in two main steps. This is the diffusion of MO from the solution to the adsorbent, followed by its attachment to the surface of the adsorbent. This can also be seen in Figure 4, which shows that the adsorption of $\mathrm{MO}$ on the four adsorbents takes place in two main phases.

Table 3. Characteristics of kinetic models of MO adsorption on the four adsorbents.

\begin{tabular}{|c|c|c|c|c|c|c|c|c|c|}
\hline \multirow{2}{*}{ Adsorbents } & \multicolumn{3}{|c|}{ Pseudo first order kinetic model } & \multicolumn{3}{|c|}{ Pseudo-second order kinetic model } & \multicolumn{3}{|c|}{ Kinetic model of intra-particle diffusion } \\
\hline & $\mathrm{q}_{\mathrm{m}}(\mu \mathrm{mol} / \mathrm{g})$ & $\mathbf{k}_{1}(\min -1)$ & $\mathbf{R}^{2}$ & $\mathrm{q}_{\mathrm{e}}(\mu \mathrm{mol} / \mathrm{g})$ & $\mathrm{k}_{2}(\mu \mathrm{mol} / \mathrm{g} / \mathrm{min})$ & $\mathbf{R}^{2}$ & $\mathrm{k}_{\text {int }}\left(\mu \mathrm{mol} / \mathrm{g} \cdot \mathrm{min}^{1 / 2}\right)$ & $\lambda$ & $\mathbf{R}^{2}$ \\
\hline $\mathrm{BN}$ & 0.78 & 0.08 & 0.16 & 3.42 & 0.01 & 0.99 & 0.64 & 1.33 & 0.59 \\
\hline BA & 2.48 & 0.09 & 0.23 & 27.17 & 1.04 & 0.99 & 4.56 & 11.18 & 0.51 \\
\hline CA1 & 10.94 & 0.13 & 0.67 & 37.73 & 1.42 & 0.99 & 6.68 & 14.15 & 0.58 \\
\hline $\mathrm{CA} 2$ & 10.75 & 0.34 & 0.68 & 16.63 & 0.01 & 0.99 & 2.91 & 5.97 & 0.59 \\
\hline
\end{tabular}

BN: native biosorbent; BA: activated biosorbent; CA1 activated carbon based on BN; CA2 activated carbon based on BA;

During the first phase, diffusion is very rapid and is characterized by the rapid migration of MO in a very short time, from the solution to the surface of the adsorbent (Figure 4). This rapid diffusion of MO onto the adsorbent is also favoured by the phenomenon of chemical attraction that exists between them (effect of $\mathrm{pH}$ ). Indeed, the availability of active sites on the surface of the adsorbent and the electrochemical attraction phenomenon that exists between the MO and the adsorbent, promote a rapid flow of MO molecules to the adsorbent. The second phase is characterized by the rapid attachment of the MO to the surface of the adsorbent until the saturation of its available pores. This saturation is characterized by the adsorption peak observed around the third minute. Since the pores available on the surface of the adsorbent are saturated, the amount of MO adsorbed decreases, but becomes constant over time due 
to the intra-particulate diffusion, which is very slow [20].

\subsubsection{Adsorption Isotherm}

Modeling of experimental MO adsorption data according to Freundlich shows the highest correlation coefficients (Table 4).
Therefore, the Freundlich model is best suited to explain the mechanisms of MO adsorption to the surface of the 4 adsorbents. So the adsorbed MO molecules are heterogeneously distributed on the surface of the adsorbent [16].

Table 4. Parameters of the Langmuir and Freundlich models, characteristics of the adsorption of methyl orange on the four adsorbents produced from peanut shells.

\begin{tabular}{llllll}
\hline \multirow{2}{*}{ Adsorbent } & Langmuir & & & \multicolumn{2}{c}{ Freundlich } \\
\cline { 2 - 6 } & $\mathbf{q}_{\mathbf{m}}(\boldsymbol{\mu} \mathbf{m o l} / \mathbf{g})$ & $\mathbf{k}_{\mathbf{l}}$ & $\mathbf{R}^{\mathbf{2}}$ & $\mathbf{n}$ & $\mathbf{k}_{\mathbf{f}}$ \\
\hline BN & 32.15 & 0.46 & 0.9013 & 0.942 & 0.998 \\
BA & 39.21 & 6.89 & 0.834 & 0.238 & 1.092 \\
CA1 & 208.33 & 0.16 & 0.8267 & 0.21 & 0.999 \\
CA2 & 62.111 & 1.025 & 0.7365 & 1.29 & 1.022 \\
\hline
\end{tabular}

$\mathrm{BN}$ : native biosorbent; BA: activated biosorbent; CA1 activated carbon based on BN; CA2 activated carbon based on BA; $\mathrm{K}_{\mathrm{f}}$ adsorption capacity, $\mathrm{n}$ adsorption intensity, $\mathrm{R}^{2}$ correlation coefficients, $\mathrm{q}_{\mathrm{m}}$ maximum adsorption capacity of the dye (forming a monolayer) per unit weight of adsorbent.

In fact, the heterogeneity of the distribution of MO at the surface of the adsorbent is due either to poor spatial distribution of the pores on the surface of the adsorbent, or to the existence of pores of very varied diameters. This phenomenon may be due to the nature of the substrate (peanut shells), because the spatial distribution of the pores on the surface of an adsorbent is necessarily due to the structural configuration of its chemical constituents (cellulose, hemicellulose and lignin). This phenomenon can also be due to the treatment given to the substrate, because the size of the pores formed on the surface of the adsorbent often varies depending on the temperature of the pyrolysis [21].

\section{Conclusion}

This work was to study the ability to eliminate methyl orange contained in water, by adsorption on four different adsorbents based on peanut shells. It emerges from this work that the chemical and thermal treatments of the native biosorbent promote a significant increase in the specific surface area and the porosity of the new adsorbent produced (BA and CA). The zwitterionic character of the acid MO in solution favoured its attachment to the four adsorbents used, whatever the nature of the initial $\mathrm{pH}$ of the medium. The adsorption of MO to the four adsorbents produced from peanut shells was characterized by a step of very rapid diffusion of the solution to the surface of the adsorbent, followed by its fixation in the pores. Its heterogeneous distribution on the surface of the adsorbents is due to the nature of the substrate (peanut shells) on the one hand, and to the method of treatment applied to the substrate on the other hand. Finally, the maximum adsorption of $\mathrm{MO}$ is still strongly influenced by the size of the specific surface and the amount of pores available on the surface of the adsorbent. This is what justifies the fact that the adsorbents CA1 and BA presented better adsorption capacities than CA2 and BN.

\section{Acknowledgements}

The authors of this work address their gratitude to Prof.
ALI Ahmed, Head of Department of Chemical Engineering and Responsible of the Laboratory of Chemical Engineering and Environment of the University Institute of Technology (IUT) of Ngaoundere. Thank you to the Department of Applied Chemistry of National School of Agro-Industrial Sciences of the University of Ngaoundere in Cameroon.

\section{References}

[1] Aboua K. N., Soro D. B., Diarra M., Dibi K., N'guettia K. R. K., Traore K. S. 2018. Adsorption of methyl orange on activated carbons in aqueous solutions: influence of activating chemical agent concentration. Afrique Science. 14 (6) 322-331.

[2] Lei Y and Yong-ming L. 2014. The adsorption mechanism of anionic and cationic dyes by Jerusalem artichoke stalk-based mesoporous activated carbon. J. Environ. Chem. Eng. 2. 220229.

[3] Hildenbrand S., Schmahl F., Wodarz R., Kimmel R., Dartsch P. 1999. Azo dyes and carcinogenic aromatic amines in cell cultures. Int. Arch. Occup. Environ. Health. 72: M052-M056. http://dx.doi.org/10.1007/PL00014217.

[4] Akansha K., Chakraborty D., Sachan S. G. 2019. Decolorization and degradation of methyl orange by Bacillus stratosphericus SCA1007. Biocatal. Agric. Biotechnol. 18, 101044.

[5] Larakeb M., Youcef L., Achour S. 2014. Etude comparative de l'élimination du Zinc par adsorption sur la goethite et sur la bentonite de Maghnia, LARHYSS Journal. 19 (3) 87-100.

[6] Khelifi O., Nacef M., Affoune A. M. 2018a. Nickel (II) adsorption from aqueous solutions by physic-chemically modified sewage sludge, Iranian Journal of Chemistry and Chemical Engineering. 37 (1) 73-87.

[7] Sejie F. and Nadiye-Tabbiruka M. S. 2016. Removal of Methyl Orange (MO) from Water by adsorption onto Modified Local Clay (Kaolinite). Physical Chemistry. 6 (2): 39-48 http://dx.doi.org/10.5923/j.pc.20160602.02

[8] Fadhil O. H. and Eisa M. Y. 2019. Removal of Methyl Orange from Aqueous Solutions by Adsorption Using Corn Leaves as Adsorbent Material. Journal of Engineering. 55-69 https://doi.org/10.31026/j.eng.2019.04.05 
[9] Alabbad A. E. 2020, Efficient Removal of Methyl Orange from Wastewater by Polymeric Chitosaniso-vanillin. Chemistry Journal. 7, 16-25. http://dx.doi.org/10.2174/1874842202007010016

[10] Arami M., Limaee N. Y., Mahmoodi N. M., Tabrisi N. S. 2005. Removal of dyes from colored textile wastewater by orange peel adsorbent: Equilibrium and kinetic studies, Journal of Colloid and Interface Science. 288 (2). 371-376.

[11] Hazourli S., Ziati M., Hazourli A., Cherifi M. 2007. Valorisation d'un résidu naturel ligno-cellulosique en charbon actif - exemple des noyaux de dattes. Revue des énergies renouvelables, ICRESD 07 Tlemcen, 187-192.

[12] Pekkuz H., Uzun İ., Güzel F. 2008. Kinetics and thermodynamics of the adsorption of some dyestuffs from aqueous solution by poplar sawdust. Bioresource Technology. 99 (6) 2009-2017.

[13] Khelifi O., Mehrez I., Ben Salah W., Ben Salah F., Younsi M., Nacef M., Affoune A. M. 2016. Study of the adsorption of Methylene Blue (BM) from aqueous solutions on a biosorbent prepared from Algerian date stones. LARHYSS Journal. 28 (4). $135-148$

[14] Djonga W. G., Noubissié E., Noumi G. B. 2019. Discoloration test of a slaughterhouse effluent by adsorption on two adsorbents produced from sawdust of Khaya senegalensis and Pinus sp. Results in Engineering. 4. 8pp. https://doi.org/10.1016/j.rineng.2019.100068.

[15] Soudani N., Najar-Souissi S., Ouederni A. 2019. Enhanced adsorption of phenol using alkaline modified activated carbon prepared From olive stones. J. Chil. Chem. Soc. 64 (1). $4352-$ 4359. http://dx.doi.org/10.4067/s0717-97072019000104352.

[16] Battas A, El Gaidoumi A, Ksakas A, Kherbeche A. 2019. Adsorption study for the Removal of Nitrate from water using local clay. The Scientific World Journal. 10 pp. https://doi.org/10.1155/2019/9529618.

[17] Al-Ghouti Mohammad A., Da'ana Dana A. 2020. Guidelines for the use and interpretation of adsorption isotherm models: Areview. Journal of Hazardous Materials. 393 (2020). 22pp. https://doi.org/10.1016/j.jhazmat.2020.122383.

[18] Inyinbor A. A., Adekola F. A., Olatunji G. A. 2016. Kinetics, isotherms and thermodynamic modeling of liquid phase adsorption of Rhodamine B dye onto Raphia hookerie fruit epicarp. Water Resources and Industry. 15 (2016). 14-27. http://dx.doi.org/10.1016/j.wri.2016.06.001.

[19] Zewail T. M., Yousef N. S. 2015. Kinetic study of heavy metal ions removal by ion exchange in batch conical air spouted bed. Alexandria Engineering Journal. 54. 83-90. http://dx.doi.org/10.1016/j.aej.2014.11.008

[20] Alghamdi A. A., Abdel-Basit Al-Odayni A. B., Saeed W. S., Almutairi M. S., Alharthi F. A., Aouak T., Al-Kahtani A. 2019. Adsorption of Azo Dye Methyl Orange from Aqueous Solutions Using Alkali-Activated Polypyrrole-Based Graphene Oxide. Molecules. 24, 3685 1-17. http://dx.doi.org/10.3390/molecules24203685

[21] Khelifi O., Mehrez I., Younsi M., Nacef M., Affoune A. M. 2018b. Methyl orange adsorption on biosorbent derived from mango seed kernels. Larhyss Journal. 36. 145-156. 